\title{
Pengaruh Citra supermarket terhadap Loyalitas Pelanggan Melalui Kepuasan Pelanggan (Studi pada HERO supermarket Yogyakarta)
}

\author{
Nerys Lourensius L.T \\ STIE Isti Ekatana Upaweda Yogyakarta \\ Tony Wijaya \\ Universitas Negeri Yogyakarta \\ masnerys@yahoo.com \\ tonypascamm@yahoo.com
}

\begin{abstract}
Abstrak
Penelitian ini bertujuan untuk mengetahui pengaruh secara langsung citra HERO supermarket terhadap loyalitas pelanggan, mengetahui pengaruh secara tidak langsung citra HERO supermarket terhadap loyalitas pelanggan melalui kepuasan pelanggan dan mengetahui pengaruh kepuasan pelanggan HERO supermarket terhadap loyalitas pelanggan. Sampel dalam penelitian ini adalah responden yang mengunjungi HERO supermarket Yogyakarta. Sampel ditentukan secara purposive dengan kriteria melakukan pembelian minimal satu kali dalam sebulan di HERO supermarket. Analisis data menggunakan analisis jalur. Hasil penelitian menunjukkan bahwa citra supermarket berpengaruh positif secara langsung terhadap loyalitas pelanggan pada HERO supermarket Yogyakarta. Citra supermarket tidak berpengaruh secara tidak langsung terhadap loyalitas pelanggan HERO supermarket Yogyakarta melalui kepuasan pelanggan sebagai variabel intervening dan kepuasan pelanggan berpengaruh positif secara langsung terhadap loyalitas pelanggan HERO supermarket Yogyakarta.
\end{abstract}

Kata Kunci: Citra, Loyalitas Pelanggan, Kepuasan Pelanggan

\section{Pendahuluan}

Bisnis ritel meliputi seluruh aktivitas yang melibatkan penjualan barang dan jasa langsung kepada konsumen untuk kebutuhan sendiri, keluarga, atau perlengkapan rumah tangga. Beberapa pelaku bisnis ritel: (1) kelompok grosir dan hypermarket, (2) kelompok supermarket, (3) kelompok minimarket modern, (4) retailer kecil tradisional, (5) kelompok department store. Bisnis ritel di Indonesia menjadi bisnis yang menarik dan cukup pesat perkembangannya, mencakup peritel kecil, menengah dan besar. Tidak bisa dipungkiri ini menjadi daya tarik juga untuk peritel asing mencoba peruntungan bisnis di Indonesia.

Tercatat beberapa peritel asing melakukan ekspansi di Indonesia seperti Dairy Farm dengan HERO supermarket, Ahold Delhaize dengan Superindo, Carrefour-Promodes dengan Carrefour yang sekarang bertransformasi menjadi Transmart Carrefour termasuk juga peritel asing seperti SOGO, Metro, ACE Hardware dan Makro. Kedepannya situasi ini juga berpotensi menjadikan daya tarik peritel luar lainnya untuk berbisnis di Indonesia. Oleh sebab itu, agar mampu bersaing dan bertahan dalam kondisi persaingan yang semakin ketat, maka salah satu cara yang harus dilakukan oleh pelaku bisnis adalah melalui peningkatan loyalitas pelanggan (Kotler, 2005). 
Pelanggan merupakan fokus utama dalam bisnis, karena tanpa pelanggan perusahaan tidak bisa memperoleh profit untuk menjalankan usahanya (Nurhadi, 2017). Menurut Griffin (1995), loyalitas merupakan aset tak ternilai bagi perusahaan. Ada enam alasan yang menjadikan pentingnya loyalitas pelanggan bagi suatu institusi: (1) pelanggan yang ada lebih prospektif, artinya pelanggan loyal akan memberi keuntungan besar kepada institusi. (2) biaya mendapatkan pelanggan baru jauh lebih besar berbanding menjaga dan mempertahankan pelanggan yang ada. (3) pelanggan yang sudah percaya pada institusi dalam suatu urusan akan percaya juga dalam urusan lainnya. (4) biaya operasi institusi akan menjadi efisien jika memiliki banyak pelanggan loyal. (5) institusi dapat mengurangkan biaya psikologis dan sosial dikarenakan pelanggan lama telah mempunyai banyak pengalaman positif dengan institusi. (6) pelanggan loyal akan selalu membela institusi bahkan berusaha pula untuk menarik dan memberi saran kepada orang lain untuk menjadi pelanggan.(Kotler, et.al., 2002).

Begitu bermanfaatnya loyalitas pelanggan maka perusahaan harus berupaya maksimal mempertahankan pelanggan. Upaya mempertahankan pelanggan merupakan strategi dari pihak penyedia jasa dengan meningkatkan kepuasan pelanggan dalam membangun citra perusahaan (Wijaya, 2008). Pelanggan yang loyal akan menjadi modal perusahaan dalam menghadapi serangan kompetitor. Keuntungan dari adanya loyalitas pelanggan adalah berkurangnya pengaruh serangan para kompetitor dari perusahaan sejenis, tidak hanya kompetisi dalam produk namun juga kompetisi dalam hal persepsi.

Perusahaan dalam membangun citra akan melakukan promosi seluas-luasnya baik melalui iklan, sponsorship event, personal selling maupun promosi diskon. Hal ini penting untuk dilakukan karena citra dapat mempengaruhi keputusan pembelian suatu produk dan jasa (Suhartanto dan Nuralia, 2001) dalam Wijaya (2008). Strategi perusahaan dalam membangun citra diharapkan akan menaikkan citra perusahaan di benak pelanggan sehingga bisa menarik pelanggan baru ataupun menjadikan pelanggan semakin loyal terhadap produk dan jasa yang sudah mereka gunakan.

Pembentukan citra toko yang baik bertujuan untuk menciptakan loyalitas pelanggan. Peritel akan memberikan suasana yang baik dan berbeda dengan pesaing lainnya untuk menjaga dan memberikan kenyamanan bagi pelanggan. Pencitraan yang diciptakan dengan baik akan memberikan dampak yang baik pula demi tercapainya tujuan-tujuan yang ditetapkan oleh suatu perusahaan, begitu pula yang terjadi di PT. HERO Supermarket Tbk.

HERO supermarket merupakan salah satu retailer yang membuka gerainya diberbagai daerah dan tak ketinggalan di Yogyakarta. Di bawah bendera PT. HERO Hypermarket Tbk. perusahaan ini telah mengadakan aliansi strategis dengan Dairy Farm Internasional pada tahun 1999 dalam bentuk penyertaan saham langsung. Kerjasama antara keduanya ditandai pula dengan bergabungnya beberapa eksekutif Dairy Farm Internasional sebagai mitra untuk bergabungnya jajaran manajemen PT. HERO Hypermarket Tbk. Hal ini bertujuan untuk memberikan kontribusi berupa pengalaman dan keahlian internasional yang bermanfaat bagi pengetahuan dan pemahaman manajemen PT. HERO Hypermarket Tbk. Perseroan ini juga menjalankan bisnis ritel dengan brand Giant, Starmart, Guardian dan IKEA.

HERO supermarket sejak awal didirikan dengan konsep gerai modern yang menawarkan produk kualitas premium termasuk produk impor. Sasaran pelannggannya adalah segmen menengah ke atas yang mengutamakan kenyamanan berbelanja, kesegaran dan kualitas produk. Hal ini memberikan dampak pada terbatasnya kinerja HERO supermarket untuk menjangkau konsumen yang lebih luas. Terbukti dengan kebijakan restrukturisasi oleh perseroan dengan mengurangi jumlah toko HERO supermarket dan 
digantikan Giant supermarket yang masih satu perseroan untuk menjangkau target pasar lebih rendah dan bukan lokasi premium. Strategi tersebut menjadikan HERO supermarket hanya memiliki 36 toko pada 2012 dimana pada tahun 2007 berjumlah 80 toko (www.oxfordbusinessgroup.com)

Menurut hasil top brand index kategori supermarket dalam kurun waktu 2014 hingga 2016 menunjukkan bahwa HERO supermarket masuk dalam urutan tiga besar setelah Superindo, Tip-top, Giant Express dan Hari-hari. Pada tahun 2017 HERO supermarket mengalami penurunan persentase top brand index menjadi 10,2\% tapi masih menduduki posisi tiga besar. Namun, pada tahun 2018 supermarket ini tidak lagi menduduki posisi tiga besar tersebut (Top Brand Index, 2018). Berdasarkan data yang ada penting menjadi catatan bahwa citra supermarket yang ditampilkan oleh HERO supermarket belum dapat menciptakan loyalitas bagi pelanggannya secara optimal, sehingga perlu dievaluasi. Informasi mengenai citra supermarket merupakan sarana bagi pengelola HERO supermarket untuk mengevaluasi kembali citra yang selama ini ditampilkan dan pengaruhnya terhadap loyalitas pelanggan.

Untuk mendapatkan pelanggan yang mempunyai kesetiaan pada suatu perusahaan, maka kepuasan pelanggan menjadi suatu hal yang penting untuk dikeloia secara lebih serius (Utama, 2003). Kepuasan pelanggan dianggap sebagai prasyarat timbulnya perilaku loyalitas positif. Penelitian yang dilakukan oleh Rizan (2009) berjudul "Pengaruh Citra Toko, Private Brand, Dan Kualitas Pelayanan Terhadap Kepuasan Pelanggan Dan Loyalitas Pelanggan Supermarket" menyatakan bahwa kepuasan pelanggan berpengaruh signifikan terhadap loyalitas pelanggan sebesar 33,9\%. Dalam penelitian yang dilakukan oleh Leliga (2013) "analisa pengaruh brand image terhadap customer loyalty dengan customer satisfaction sebagai mediator pada the dreamland luxury villas and spa, Bali" menerangkan ada pengaruh customer satisfaction terhadap customer loyalty. Penelitian ini menguatkan penelitian sebelumnya bahwa kepuasan pelanggan berpengaruh terhadap loyalitas pelanggan. Hal tersebut menunjukkan bahwa strategi kepuasan pelanggan dianggap mampu memberi pengaruh terhadap loyalitas pelanggan

Beberapa penelitian sebelumnya mengkaji citra, kepuasan dan loyalitas. Penelitian yang dilakukan oleh Prabowo (2017) menggunakan kepuasan pelanggan yang dijadikan sebagai variabel mediasi. Alasanya dipilihnya variabel kepuasan pelanggan karena menurut Kotler dan Keller (2009) kepuasan pelanggan adalah perasaan senang atau kecewa yang dirasakan seseorang yang berasal dari perbandingan antara kesannya terhadap kinerja (hasil) suatu produk dan harapan-harapannya, dengan kata lain kepuasan sebagai evaluasi paska konsumsi dimana suatu alternatif yang dipilih setidaknya memenuhi atau melebihi harapan. Penelitian yang dilakukan oleh Wijaya (2008) yang bertujuan untuk menguji pengaruh penanganan keluhan dan citra perusahaan terhadap loyalitas konsumen Natasha skin care. Hasil penelitian menunjukkan ada pengaruh penanganan komplain dan citra perusahaan terhadap loyalitas pelanggan secara parsial maupun simultan. Hasil penelitian menunjukkan hasil yang sama dengan penelitian yang dilakukan oleh Andreassen (1999). Berdasarkan latar belakang yang telah diuraikan di atas, penelitian yang dilakukan bertujuan menguji pengaruh citra HERO supermarket secara langsung terhadap loyalitas pelanggan maupun secara tidak langsung terhadap loyalitas pelanggan melalui kepuasan pelanggan. 


\section{Landasan Teori dan Pengembangan Hipotesis}

Customer loyalty atau loyalitas pelanggan adalah komitmen pelanggan terhadap suatu merek, toko atau pemasok berdasarkan sifat yang sangat positif dalam pembelian jangka panjang (Tjiptono, 2000). Mowen dan Minor (1998) mendefinisikan loyalitas sebagai kondisi di mana pelanggan mempunyai sikap positif terhadap suatu merek, mempunyai komitmen pada merek tersebut, dan bermaksud meneruskan pembeliannya di masa mendatang. Menurut Sutisna dalam Wijaya (2008), loyalitas konsumen dapat dikelompokkan menjadi dua bagian yaitu:

1) Loyalitas merek (brand loyalty)

Loyalitas merek dapat didefinisikan sebagi sikap menyenangi terhadap suatu merek yang dipresentasikan dalam pembelian yang konsisten terhadap merek itu sepanjang waktu.

2) Loyalitas toko (store loyalty)

Loyalitas toko adalah loyalitas konsumen dalam emngunjungi suatu toko dimana disitu konsumen biasa membeli merek produk yang diinginkan. Sehingga pelanggan/konsumen enggan berpindah ke toko lain.

Brand image merupakan variabel paling dominan dalam menggerakkan loyalitas konsumen (Absharina, 2015). Menurut Keller dan Aaker (1992), kredibilitas perusahaan berkenaan dengan tingkat dimana konsumen percaya bahwa perusahaan dapat mendesain dan mengirimkan produk dan service yang dapat memuaskan kebutuhan dan keinginan konsumen. Kotler (2009) mendefinisikan citra sebagai seperangkat keyakinan, ide, dan kesan bahwa seseorang memegang tentang obyek Citra merupakan aset tidak berwujud (intangible assets) yang berharga dari perusahaan (Hidajahningtyas 2013). Sebuah citra yang baik akan meningkatkan kepuasan pelanggan, kualitas layanan, loyalitas, dan niat pembelian kembali (Bloemer et al., 1998;. Da Silva et.al., 2008 dan. Lai et al.,2009) dalam Hidajahningtyas,2013. Andreassen and Lindestead dalam Andreassen (1999) yang dikutip oleh Wijaya (2008) menyatakan bahwa semua industri yang diteliti dalam Norwegian Customer Satisfaction Barometer, terdapat korelasi positif antara citra perusahaan dengan kepuasan pelanggan dan kepuasan pelanggan memiliki korelasi positif dengan loyalitas konsumen. Prabowo (2017) mengungkapkan bahwa citra toko positif berpengaruh signifikan terhadap loyalitas pelanggan pada GMT swalayan. Hasil koefisien regresi pada penelitian tersebut $(B 1=0,342$ (positif), sig $=(0,000)<0,05)$ juga membuktikan bahwa kenaikan citra toko berpengaruh terhadap peningkatan loyalitas pelanggan di GMT swalayan. Hal ini menunjukkan bahwa bila brand image meningkat, maka loyalitas pelanggan juga akan meningkat.

Engel (1990) menyatakan bahwa kepuasan pelanggan merupakan evaluasi setelah pembelian di mana produk yang dipilih sekurang-kurangnya sama atau melebihi harapan pelanggan, sedangkan ketidak-puasan timbul apabila hasil (outcome) tidak memenuhi harapan. Kotler $(2000,36)$ mendefinisikan kepuasan pelanggan sebagai perasaan suka/tidak seseorang terhadap suatu produk setelah ia membandingkan prestasi produk tersebut dengan harapannya. Bloemer and Ruyter (1998) dalam Sondoh (2007) menyatakan bahwa kepuasan pelanggan merupakan mediator antara citra toko dengan loyalitas pelanggan. Kepuasan pelanggan adalah tanggapan emosional yang positif pada evaluasi terhadap pengalaman dalam menggunakan suatu produk atau jasa (Wilkie, 1994). Kepuasan menunjukkan kemampuan suatu produk dalam memenuhi tujuan pelanggan (Oliver, 1999). Kepuasan tersebut berpengaruh positif terhadap loyalitas pelanggan (Sondoh dkk., 2007 ; Andreani 
dkk., 2012). Kepuasan pelanggan juga diketahui berpengaruh positif dan signifikan terhadap loyalitas pelanggan. Prabowo (2017) menambahkan bahwa pengaruh citra toko dan kepuasan pelanggan pada studi GMT swalayan berpengaruh signifikan terhadap loyalitas pelanggan. Satisfaction has been noted to be treated as a mediator between store image and loyalty (Bloemer \& Ruyter, 1998) dalam Sondoh 2007.

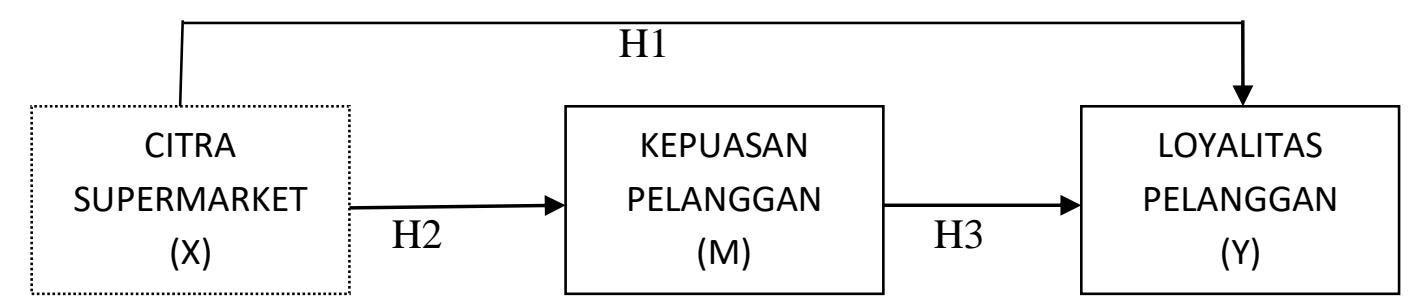

Gambar 1. Model Penelitian

Keterangan :

$X$ : variabel independen

$\mathrm{M}$ : variabel mediasi

Y : variabel dependen

Hipotesis yang diajukan dalam penelitian yaitu:

H1: ada pengaruh positif secara langsung antara citra supermarket terhadap loyalitas pelanggan

H2: ada pengaruh positif secara langsung antara citra supermarket terhadap kepuasan pelanggan

H3: ada pengaruh positif secara langsung antara kepuasan pelanggan terhadap loyalitas pelanggan

\section{Metode Penelitian}

\section{Populasi dan Sampel Penelitian}

Populasi

Populasi dalam penelitian ini adalah seluruh pengunjung HERO supermarket Yogyakarta

\section{Sampel}

Sampel dalam penelitian ini adalah responden yang mengunjungi HERO supermarket Yogyakarta. Metode pengambilan sampel secara pemilihan non probabilitas berupa purposive sampling dengan kriteria melakukan pembelian minimal dalam sebulan di HERO supermarket. Penentuan responden tersebut ditentukan berdasarkan pendapat dari Hair (2010), ukuran responden yang ideal dan representative adalah tergantung pada jumlah semua indikator pada variabel dikalikan 5-10. Dalam penelitian ini jumlah sampel sebanyak 162 


\section{Definisi Operasional dan Pengukuran Variabel Variabel Independen $(\mathrm{X})$}

Dalam penelitian ini yang menjadi variabel independen adalah:

\section{Citra (X)}

Definisi citra dalam penelitian ini mengacu pada kotler (2000) yang mendefinisikan citra sebagai kumpulan keyakinan-keyakinan, ide-ide dan kesan-kesan atas suatu obyek dari sudut pandang seseorang. Perusahaan harus mampu membuktikan bahwa perusahaan tersebut dapat dipercaya. Memiliki image yang baik dimata masyarakat akan menjadi konsekuensi dari pembentukan citra. Citra dapat mendukung dan merusak nilai yang konsumen rasakan. Citra yang baik akan mampu meningkatkan kesuksesan suatu perusahaan dan sebaliknya citra yang buruk akan memperpuruk kestabilan suatu perusahaan

Andreassen (1999) dalam Wijaya (2008) mengukur menggunakan corporate image scale yang dibuat dalam itemized rating scale 5 poin dengan pernyataan penilaian negatif atau positif persepsi konsumen terhadap perusahaan, sepuas apakah konsumen terhadap pernyataan diri dari perusahaan terhadap publik, seberapa tinggi orientasi perusahaan pada konsumen dan penilaian positif atau negatif hubungan konsumen dengan perusahaan.

\section{Variabel terikat (Y)}

Variabel dependen dalam penelitian ini adalah loyalitas pelanggan. Loyalitas pelanggan adalah perilaku pelanggan yang ditunjukkan dari kemauan pelanggan untuk membeli ulang atau berlangganan berbelanja di HERO supermarket Yogyakarta. Loyalitas diukur dengan loyalty scale yang digunakan dalam penelitian Andreassen (1999) dalam itemized rating scale 5 poin dengan pernyataan seberapa besar kemungkinan konsumen tetap menjadi pelanggan perusahaan dan seberapa besar keinginan untuk memberi rekomendasi terhadap orang lain.

\section{Variabel Penghubung (Mediating Variable)}

Variabel mediasi (M) atau mediating variabel adalah variabel yang mempengaruhi fenomena yang diobservasi (variabel dependen), variable mediasi sering disebut dengan variabel intervensi (intervening variable), karena memediasi atau mengintervensi hubungan kasual variabel independen ke variabel dependen (Jogiyanto, 2004).

Dalam penelitian ini peneliti menetapkan kepuasan pelanggan (M) sebagai variabel intervening atau mediasi. Kepuasan pelanggan adalah perasaan senang atau kecewa seseorang yang berasal dari perbandingan antara kesannya terhadap kinerja atau hasil suatu produk dan harapan-harapan Kotler, et al., (2000). Kepuasan konsumen dalam penelitian ini menggunakan indikator dari Nilawan dalam Graha (2006) yaitu: lokasi toko, kelengkapan barang yang dijual, harga barang, pelayanan tenaga penjual dalam membantu pelanggan, kenyamanan berbelanja di tempat ritel dan garansi barang.

\section{Uji Instrumen \\ Uji Validitas}

Uji validitas dilakukan untuk mengetahui kemampuan instrumen dalam mengukur variabel penelitian. Pengujian ini dilakukan dengan mengajukan butir-butir pernyataan kuesioner yang nantinya diberikan kepada responden. Tingkat kevalidan instrumen penelitian ini diketahui melalui uji validitas dengan menggunakan program SPSS Windows 23. Butirbutir penyataan yang mempunyai factor loading yang valid yaitu $r$ hitung $>$ daripada $r$ table 
menunjukkan bahwa indikator-indikator yang ada merupakan satu kesatuan alat ukur yang mengukur suatu konstruk yang sama dan dapat memprediksi apa yang seharusnya dapat diprediksi. Semua butir pernyataan kuesiner dalam penelitian ini masuk kriteria valid

\section{Uji Reliabilitas}

Suharsimi Arikunto (2002) menyatakan: "Reliabilitas menunjukan pada satu pengertian bahwa instrumen cukup dapat dipercaya untuk digunakan sebagai alat pengumpulan data karena instrumen tersebut sudah baik". Uji reliabilitas menggunakan rumus Alpha Cronbac. Semua variable dalam penelitian ini reliabel

\section{Teknik Analisis Data}

\section{a. Uji Asumsi Klasik}

1) Uji Normalitas

Uji normalitas bertujuan untuk menguji apakah data yang akan digunakan dalam model regresi berdistribusi normal atau tidak (Ghozali, 2005). .

2) Uji Multikolinearitas

Uji multikolinieritas bertujuan untuk menguji apakah model regresi ditemukan adanya korelasi antar variabel independen. Model regresi yang baik seharusnya tidak terjadi korelasi di antara variabel independen.

3) Uji Heterokodastisitas

Uji heteroskodastisitas bertujuan menguji apakah dalam model regresi terjadi ketidaksamaan variance dari residual satu pengamatan ke pangamatan yang lain tetap, maka disebut heterokodastisitas (Ghozali,2011).

\section{b. Analisis Jalur}

Model path analisis (analisis jalur) merupakan perluasan dari analisis regresi linier berganda atau analisis jalur adalah penggunaan analisis regresi untuk menaksir hubungan kausalitas antar variabel yang telah ditetapkan sebelumnya berdasarkan teori Ghozali, (2011). Path analisis digunakan untuk menganalisis pola hubungan antar variabel dengan tujuan untuk mengetahui pengaruh langsung maupun tidak langsung seperangkat variabel bebas (eksogen) terhadap variabel terikat (endogen).

Manfaat dari path analisis adalah untuk penjelasan terhadap fenomena yang dipelajari atau permasalahan yang diteliti, prediksi dengan path analysis ini bersifat kualitatif, faktor determinan yaitu penentuan variabel bebas mana yang berpengaruh dominan terhadap variabel terikat, serta dapat menelusuri mekanisme pengaruh variabel bebas terhadap variabel terikat. Variabel intervening merupakan variabel antara atau mediating, fungsinya memediasi antara variabel independen dengan variable dependen. Untuk menguji pengaruh variabel intervening digunakan metode analisis jalur (path analysis) (Engkos dan Riduwan, 2012:2). Berdasarkan hubungan antar variabel, berikut adalah model penelitian dalam bentuk diagram jalur.

Model analisis jalur di atas digunakan untuk mencari pengaruh langsung dan tidak langsung antara variabel independen dan variable dependen. Persamaan dalam model ini terdiri dari dua tahap, yaitu :

$$
\mathrm{Y}_{1}=\beta_{1} \mathrm{X}_{1}+\mathrm{e}_{1}
$$




\section{Dimana :}

$\mathrm{X}_{1}$ : Citra supermarket,

$\mathrm{Y}_{1}$ : Kepuasan pelanggan,

$\beta_{1}$ : koefisien untuk variabel Citra supermarket,

$\mathrm{e}_{1}$ : error

$$
\mathrm{Y}_{2}=\beta_{1} \mathrm{X}_{1}+\beta_{2} \mathrm{X}_{2}+\mathrm{e}_{2}
$$

Dimana :

$\mathrm{X}_{1}$ : Citra supermarket,

$\mathrm{X}_{2}$ : Kepuasan pelanggan,

$\mathrm{Y}_{2}$ : Loyalitas pelanggan,

$\beta_{1}$ : koefisien untuk variabel Citra supermarket,

$\beta_{2}$ : koefisien untuk variabel Kepuasan Pelanggan

$\mathrm{e}_{2}$ : error

Analisis jalur (Path analysis) dalam penelitian ini adalah kepuasan pelanggan. Analisis jalur akan membantu dalam melihat besarnya koefisien secara langsung dan tidak langsung dari variabel terikat terhadap variabel bebas, dengan memperhatikan besarnya koefisien. maka bisa di bandingkan besarnya pengaruh secara langsung dan tidak langsung. Berdasarkan nilai koefisien tersebut, akan di ketahui variabel mana yang memberikan pengaruh terbesar dari pengaruh terkecil terhadap variabel terikat. Berikut gambar model analisis jalur pada penelitian ini :

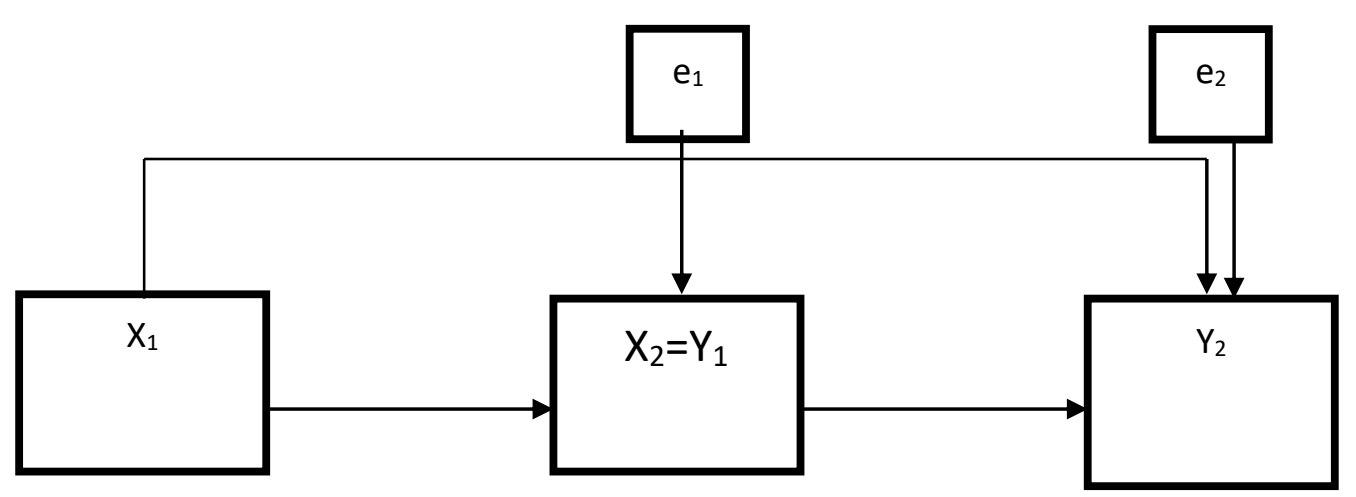

Gambar 2. Model Analisi Jalur

\section{Hasil dan Pembahasan \\ Uji Prasyarat Analisis}

\section{Uji normalitas}

Hasil uji normalitas menunjukkan nilai signifikansi semua variabel lebih dari 0,05 . Sehingga dapat disimpulkan bahwa semua variabel data penelitian berdistribusi normal. 


\section{Uji multikolinieritas}

Hasil uji multikolinearitas menunjukkan bahwa bahwa semua variabel mempunyai nilai toleransi di atas 0,1 dan nilai VIF di bawah 10, sehingga dapat disimpulkan bahwa model regresi pada penelitian ini tidak terjadi multikolinieritas.

\section{Uji heterokodastistas}

Hasil uji heteroskedastisitas menunjukkan bahwa bahwa semua variabel mempunyai nilai signifikansi lebih besar dari 0.05 sehingga dapat disimpulkan bahwa model regresi pada penelitian ini tidak terjadi heteroskedastisitas.

\section{Analisis Regresi Model 1}

Analisis regresi model 1 (satu) digunakan untuk mengetahui kekuatan hubungan dari variabel bebas (independent) terhadap variabel mediasi (intervening). Pada analisis regresi model 1 (satu) persamaan strukturalnya adalah:

Kepuasan $=\beta_{1}$ Citra supermarket $+\mathrm{e}_{1}$

\section{Uji Signifikansi paremeter individual (uji t)}

Uji parsial digunakan untuk menguji pengaruh Citra supermarket $\left(\mathrm{X}_{1}\right)$ terhadap kepuasan $\left(\mathrm{Y}_{1}\right)$ secara parsial. Hasil analisis statistik uji t dapat dilihat sebagai berikut:

Tabel 1. Uji Signifikansi paremeter individual (uji t)

\begin{tabular}{|c|c|c|c|}
\hline & B & t & sig \\
\hline Konstanta & 36,033 & 9,057 & 0,000 \\
\hline$X_{1}$ & 0,941 & 7,626 & 0,000 \\
\hline
\end{tabular}

Sumber : Data primer yang diolah 2019

Berdasarkan hasil uji SPSS di atas, maka persamaan regresi yang mencerminkan variabel-variabel dalam penelitian ini adalah:

$\mathrm{Y}_{1}=36,033+0,941 \mathrm{X}_{1}+\mathrm{e}_{1}$

Keterangan:

$\mathrm{Y}_{1}=$ Kepuasan

$\mathrm{X}_{1}=$ Citra Supermaket

$\mathrm{e}_{1}=$ Error

Berdasarkan pengujian SPSS parameter individual, diperoleh hasil pengujian individual citra supermarket menunjukkan nilai unstandardized coefficients beta sebesar 0,941 dan juga signifikan pada $<0,05$ yang berarti citra supermarket berpengaruh positif signifikan terhadap kepuasan pelanggan.

\section{Koefisien Determinasi $\left(\mathbf{R}^{2}\right)$}

Hasil analisis SPSS model summary menunjukan bahwa besarnya R Square adalah 0,262 atau $26,2 \%$. Variabel kepuasan pelanggan dapat dijelaskan oleh variabel citra supermarket sebesar 26,2\% dan 73,8\% sisanya dijelaskan oleh variabel lain diluar model. 


\section{Analisis Regresi Model 2}

Analisis regresi model 2 (dua) digunakan untuk mengetahui kekuatan hubungan dari variabel bebas (independent) terhadap variabel terikat (dependent). Pada analisis regresi model 2 persamaan strukturalnya adalah:

Loyalitas $=\beta_{1}$ citra suermarket $+\beta_{2}$ Kepuasan pelanggan $+\mathrm{e}_{2}$

1) Uji Signifikansi paremeter individual (uji t)

Hasil analisis statistik uji t dapat dilihat sebagai berikut:

Tabel 2. Uji Signifikansi Paremeter Individual (uji t)

\begin{tabular}{|c|c|c|c|}
\hline & B & t & Sig \\
\hline Konstanta & -7.351 & -4.020 & 0,000 \\
\hline$X_{1}$ & 0,369 & 6.858 & 0,000 \\
\hline$X_{2}$ & $.0,64$ & 5.536 & 0,000 \\
\hline
\end{tabular}

Sumber : Data primer yang diolah 2019

Berdasarkan hasil uji SPSS di atas, maka persamaan regresi yang mencerminkan variabel-variabel dalam penelitian ini adalah:

$\mathrm{Y}_{2}=-7.351+0.369 \mathrm{X}_{1}+0.164 \mathrm{X}_{2}+\mathrm{e}_{2}$

Keterangan:

$\mathrm{Y}_{2}=$ Loyalitas

$\mathrm{X}_{1}=$ Citra supermarket,

$\mathrm{X}_{2}=$ Kepuasan pelanggan,

$\mathrm{e}_{2}=$ Error

Berdasarkan pengujian SPSS parameter individual, diperoleh hasil pengujian individual citra supermarket menunjukkan nilai unstandardized coefficients beta sebesar 0,369 dan menunjukkan nilai signifikan pada < 0,05, maka H1 diterima. Kesimpulan bahwa variabel citra supermarket berpengaruh positif signifikan secara langsung terhadap loyalitas pelanggan.

Hasil pengujian individual kepuasan pelanggan menunjukkan nilai unstandardized coefficients beta sebesar 0,164 dan menunjukkan signifikan pada $<0,05$, maka H3 diterima. Kesimpulan bahwa variabel kepuasan pelanggan berpengaruh positif signifikan secara langsung terhadap loyalitas pelanggan.

2) Koefisien Determinasi $\left(\mathrm{R}^{2}\right)$

Hasil analisis SPSS model summary menunjukan bahwa besarnya R Square adalah 0,494 atau 49,4\%. Variabel loyalitas pelanggan dapat dijelaskan oleh citra supermarket sebesar 49,4\% dan 50,6\% sisanya dijelaskan oleh variabel lain diluar model.

\section{Analisis jalur}

Analisis jalur merupakan perluasan dari analisis regresi linear berganda. Analisis regresi dilakukan sebanyak dua kali. Analisis regresi yang pertama untuk mengetahui 
kekuatan hubungan dari variabel bebas (independent) terhadap variabel mediasi (intervening). Analisis regresi yang kedua untuk mengetahui kekuatan hubungan dari variabel bebas (indenpendent) terhadap variabel terikat (dependent).

\section{a) Intepretasi Analisis Jalur}

Berdasarkan uji t yang tampak pada tabel 1 diperoleh nilai unstandardized coefficients beta variabel citra supermarket sebesar 0,941. Nilai unstandardized coefficients beta sebesar 0,941 merupakan nilai path atau jalur P1. Berdasarkan uji t yang tampak pada tabel 3 diperoleh nilai unstandardized coefficients beta pada variabel citra supermarket sebesar 0,369. Nilai unstandardized coefficients beta sebesar 0,369 merupakan nilai path atau jalur P2. Nilai unstandardized coefficients beta variabel kepuasan pelanggan sebesar 0,164 . Nilai unstandardized coefficients beta sebesar 0,164 merupakan nilai path atau jalur P3. Berdasarkan uji $\mathrm{R}^{2}$ yang tampak pada Gambar 3. diperoleh nilai

$$
e_{1}=\sqrt{1-R^{2}}=\sqrt{1-0,262}=\sqrt{0,378}=0,859
$$

Pengaruh kausal empiris antara variabel $\left(\mathrm{X}_{1}\right)$ citra supermarket terhadap kepuasan pelanggan $\left(\mathrm{Y}_{1}\right)$ dapat digambarkan melalui persamaan struktural 1 (satu), yaitu:

Kepuasan pelanggan $=\beta_{1}$ Citra supermarket $+e_{1}$ Atau

kepuasan pelanggan $=0,941$ citra supermarket $+0,859$ e1

Berdasarkan uji $\mathrm{R}^{2}$ yang tampak pada Gambar 3 diperoleh nilai

$$
e_{2}=\sqrt{1-R^{2}}=\sqrt{1-0,494}=\sqrt{0,506}=0,711
$$

Pengaruh kausal empiris antara variabel $\left(\mathrm{X}_{1}\right)$ citra supermarket terhadap kepuasan pelanggan $\left(\mathrm{Y}_{1}\right)$ dapat digambarkan melalui persamaan struktural 2 (dua), yaitu:

Loyalitas $=\beta_{1}$ citra supermarket $+\beta_{2}$ kepuasan pelanggan $+\mathrm{e}_{2}$

Atau

Loyalitas $=0,369$ citra supermarket $+0,169$ kepuasan pelanggan $+0,711 \mathrm{e}_{2}$

Intepretasi dari hasil analisis jalur dapat dilihat pada gambar 3 berikut: 


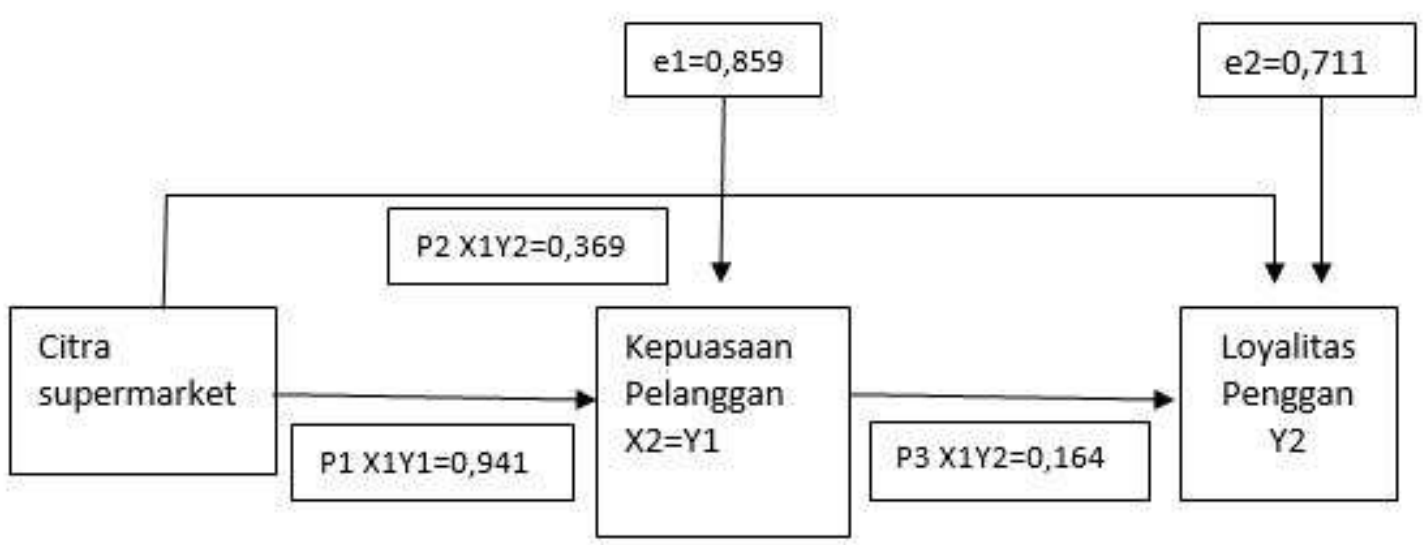

Gambar 3. Hasil analisis jalur (Sumber : Data primer yang diolah 2019)

Tabel 3. Hasil estimasi parameter model

\begin{tabular}{|l|l|l|l|l|}
\hline Model & $\begin{array}{l}\text { Unstandardized } \\
\text { coefficients beta }\end{array}$ & t & Sig & R2 \\
\hline persamaan struktural 1 (X1 ke Y1) & \\
\hline X1=P1 X1Y1 & 0,941 & 7.626 & 0.000 & 0,262 \\
\hline persamaan struktural 2 (X1 Y1 ke Y2) \\
\cline { 1 - 4 } X1=P2 X1Y2 & 0,369 & 6.858 & 0.000 & \multirow{2}{*}{0.494} \\
\hline Y1=P3 Y1Y2 & 0,164 & 5.536 & 0,000 & \\
\hline
\end{tabular}

Sumber : Data primer yang diolah 2019

b) Pengaruh Langsung dan Tidak Langsung

Pada model jalur, penelitian ini akan menjelaskan pengaruh langsung dan tidak langsung variabel exogenenous terhadap variabel endogeneous.

1) Pengaruh Citra supermarket terhadap Loyalitas pelanggan

Pengaruh langsung $\left(\mathrm{X}_{1} \mathrm{Y}_{1}\right) \quad=0,369$

Pengaruh tidak langsung melalui kepuasan

$\mathrm{X}_{1} * \mathrm{Y}_{1}=(0,941) *(0,164) \quad=0,154$

Apabila pengaruh tidak langsung lebih besar dari pada pengaruh langsung maka dapat disimpulkan bahwa hubungan yang sebenarnya adalah tidak langsung atau variabel mediating. Dari hasil tersebut dapat disimpulkan bahwa citra supermarket tidak berpengaruh secara tidak langsung terhadap loyalitas pelanggan. Hal ini disebabkan nilai direct effect lebih besar dari indirect effect $(0,369>0,154)$. 
Tabel 4. Hasil Analisis Pengaruh Langsung dan Tidak Langsung

\begin{tabular}{|l|l|l|l|l|l|}
\hline variabel & Direct & Indirect & Total & Kriteria & Kesimpulan \\
\hline $\begin{array}{l}\text { Citra } \\
\text { supermarket }\end{array}$ & 0,369 & 0,154 & 0,523 & $\begin{array}{l}\text { direct effect } \\
\text { Indirect } \\
\text { Intervening }\end{array}$ & $\begin{array}{l}\text { Kepuasan } \\
\text { bukan } \\
\text { sebagai } \\
\text { variabel } \\
\text { intervening }\end{array}$ \\
\hline
\end{tabular}

Sumber : Data primer yang diolah 2019

Berdasarkan uraian tabel di atas, maka pengaruh tidak langsung citra supermarket $\left(\mathrm{X}_{1}\right)$ terhadap loyalitas pelanggan $\left(\mathrm{Y}_{2}\right)$ melalui kepuasan pelanggan $\left(\mathrm{Y}_{1}\right)$ sebesar $0,154<$ pengaruh langsung citra supermarket $\left(\mathrm{X}_{1}\right)$ terhadap loyalitas pelanggan $\left(\mathrm{Y}_{2}\right)$ sebesar 0,369 . Dengan demikian $\mathbf{H 2}$ ditolak. Dari hasil tersebut dapat diketahui bahwa citra supermarket tidak berpengaruh terhadap loyalitas pelanggan melalui kepuasan pelanggan. Jadi dapat disimpulkan bahwa kepuasan pelanggan tidak menjadi variabel intervening antara citra supermarket terhadap Loyalitas pelanggan.

\section{Pembahasan}

Citra supermarket memiliki pengaruh positif secara langsung terhadap loyalitas pelanggan HERO supermarket Yogyakarta. Hal ini disebabkan nilai signifikansi lebih kecil dari taraf signifikansi yang ditentukan. Di samping itu sebagian besar responden menyatakan loyal untuk berbelanja di HERO supermarket. Hal ini menunjukan bahwa citra supermarket merupakan salah satu penentu loyalitas pelanggan karena citra supermarket yang baik akan menciptakan dan mempertahankan loyalitas pelanggan. Jadi semakin tinggi citra supermarket yang diterapkan, akan meningkatkan loyalitas. Hasil penelitian ini mendukung hasil penelitian sebelumnya yang dilakukan oleh Prabowo tahun 2017 yang bertujuan untuk menganalisis pengaruh Citra Toko dan Kepuasan Pelanggan terhadap Loyalitas Pelanggan di GMT Swalayan Sleman, Yogyakarta.

Kepuasan pelanggan dalam model penelitian ini tidak memediasi hubungan antara citra supermarket terhadap loyalitas pelanggan HERO supermarket Yogyakarta. Variabel kepuasan pelanggan tidak mengakibatkan variabel citra supermarket mempengaruhi variabel loyalitas pelanggan secara tidak langsung. Hal ini ditunjukkan dari nilai pengaruh tidak langsung variabel citra supermarket terhadap loyalitas pelanggan melalui variabel kepuasan pelanggan nilainya lebih kecil dari nilai pengaruh langsung variabel citra supermarket terhadap loyalitas pelanggan. Di samping itu sebagian besar responden menyatakan tertarik berbelanja di HERO supermarket.

Kepuasan pelanggan berpengaruh positif signifikan secara langsung terhadap loyalitas pelanggan HERO supermarket Yogyakarta. Hal ini disebabkan nilai sig. lebih kecil dari taraf signifikansi yang ditentukan. Hal ini menunjukan bahwa kepuasan pelanggan merupakan salah satu penentu loyalitas pelanggan karena kepuasan pelanggan akan menciptakan loyalitas pelanggan. Jadi semakin tinggi kepuasan yang diterapkan, akan meningkatkan loyalitas.

\section{Simpulan}

Berdasarkan hasil hasil penelitian maka dapat disimpulkan bahwa citra supermarket berpengaruh positif secara langsung terhadap loyalitas pelanggan pada HERO supermarket Yogyakarta. Citra supermarket tidak berpengaruh secara tidak langsung terhadap loyalitas 
pelanggan HERO supermarket Yogyakarta melalui kepuasan pelanggan sebagai variabel intervening. Kepuasan pelanggan berpengaruh positif secara langsung terhadap loyalitas pelanggan HERO supermarket Yogyakarta. Penelitian ini memiliki keterbatasan terkait aspek personal dan demografi dari responden, penelitian selanjutnya dapat mempertimbangkan aspek tersebut dalam mengkaji loyalitas pelanggan. Penelitian selanjutnya juga dapat memperluas sampel agar hasil yang diperleh lebh bervariatif.

\section{Daftar Pustaka}

Aaker, David A and Kevin Lane Keller (1992). The effect of Sequential Introduction of Brand Extensions. Journal of Marketing Research 29.

Andreani, Fransisca dkk, (2012), The Impact Of Brand Image, Customer Loyalty With Customer Satisfaction as A Mediator In Mcdonald's, Jurnal Manajemen dan Kewirausahaan, vol 14 no 1, Surabaya.

Andreassen, Tor Wallin, (1999), "What Drives Customer Loyalty with Complaint Resolutiont?", Journal of Service Research 1 (4)

Andreassen, T.W. \& Lindestad, B. (1998). Customer Loyalty and Complex Service; The Impact of Corporate Image on Quality, Customer Satisfaction and Loyalty for Coustomers with Varrying Degrees of Service Expertise. Int J. Serv. Ind. Manage.

Arikunto, Suharsimi. (2002). Prosedur Penelitian Suatu Pendekatan Analisis. Jakarta: Rineka Cipta.

Engel, J.F., et.al (1990), Consumer Behavior, Sixth Edition, The Dryden Press, Chicago

Engel, J.F, Blackwell, Rd, and Miniard, DW. (1995). Perilaku Konsumen. Jilid 1. (Boediono, Terjemahan). Jakarta: Bina Rupa Akasara.

Fajarianto, Bayu dkk, (2013), Pengaruh Kealitas Pelayanan Dan Brand Image Terhadap Loyalitas Pelanggan Melalui Kepuasan Pelanggan, Diponegoro Journal of Social and Politic, Semarang

Ghozali, Imam. (2011). Aplikai Analisis Multivarite dengan SPSS. Cetakan Keempat. Semarang: Badan Penerbit Universitas Diponegoro.

Graha, I Made Satya dan Made Wardana, (2006), Pengaruh Kualitas Pelayanan Terhadap Kepuasan Dan Loyalitas Pelanggan Hardy's Negara, E-Jurnal Ekonomi dan Bisnis Universitas Udayana 5.2 (2016) : 309-334

Griffin, J, (2005). Customer Loyalty: Menumbuhkan Dan Mempertahankan Kesetiaan Pelanggan (Terjemahan). Jakarta: Erlangga.

Griffin, Jill, (1995), Customer Loyalty: How to earn it, How to keep it, A Division of Simon and Schukers Inc., USA.

Gunawan, A.W, (27 Desember 2016), A new chapter for HERO dari www.miraeasset.co.id/files/bbs/01202/8127_1.pdf

Hair Joseph, F, et al, (2010). Multivariate Data Analysis. New Jersey: Prentice Hall Published.

Hidajahningtyas, Nurullah dkk, (2013). Pengaruh Citra, Kealitas Layanan Dan Kepuasan Terhadap Loyalitas Pasien Di Poliklinik Eksekutif Rumah Sakit Daeraah dr. Soebandi Kabupaten Jember, JEAM Vol XII No. 1/2013, Jember.

Jogiyanto, (2004). Metodologi Penelitian Bisnis : Salah Kaprah dan PengalamanPengalaman. Universitas Gadjah Mada, Yogyakarta.

Kotler, Philip, (2000). Marketing Management, The Millenium Edition, International Edition. New Jersey: Prentice Hall International Inc.,. 
, (2002), Hayes, Thomas, Bloom Paul N., "Marketing Professional Service, Prentice Ha 11 International Press. . (2005).ManajemenPemasaran. PT Indeks, Jakarta.

Kotler, Philip dan Kevin L. Keller. (2006). Manajemen Pemasaran edisi ke 12 Jilid ke 1. New Jersey, Indeks.

. (2009). Manajemen Pemasaran. (Jilid 1 dan 2). Jakarta: PT Indeks.

Leliga, Felicia Juliani, (2013), Analisa Pengaruh Brand Image Terhadap Customer Loyalty Dengan Customer Satisfaction Sebagai Mediator Pada The Dreamland and Luxury Villas and Spa Bali, Universitas Kristen Petra, Surabaya.

Lianty, Yumei dan Widyatmoko, (2011), Analisis Empiris Pengaruh Public Relations Terhadap Citra HERO Supermarket, Jurnal komunikasi universitas Tarumanegara, Jakarta.

Mardalis, Ahmad, (2005), Meraih Loyalitas Pelanggan, BENEFIT, Vol. 9, No. 2, Surakarta

Mohsan, Faizan, et al,. (2011). Impact of Customer Satisfaction on CustomerLoyalty and Intentions to Switch: Evidence from Banking Sector of Pakistan. International Journal of Business and Social Science. Vol. 2.

Nurhadi dan Asriel Azis, (2017), Pengaruh Kualitas Pelayanan Terhadap Kepercayaan dan Kesetiaan konsumen, Jurnal Economia, vol 14, no 1, Yogyakarta

Oliver, Richard L. (1999), "Whence Consumer Loyalty?, Journal of Marketing, Vol 63 (special issue) pp. 33-44.

Prabowo, D.D. (2017). Pengaruh Citra Toko dan Kepuasan Pelanggan terhadap Loyalitas Pelanggan di GMT swalayan Sleman, Yogyakarta. Skripsi. Fakultas Ekonomi dan Bisnis. Universitas Muhammadiyah Yogyakarta. Yogyakarta. 30 hal.

Prahastuti, Lina, (2011), Analisis Pengaruh Kualitas Layanan Dan Kualitas Produk Terhadap Kepuasan Konsumen Untuk Meningkatkan Loyalitas Konsumen Indosat (Studi Pada Pelanggan Indosat di Wilayah Semarang), Fakultas Ekonomi Universitas Diponegoro Semarang.

Purwadi. (2000). Riset Pemasaran Implementasi dalam Bauran Pemasaran. Jakarta: Rineka Cipta.

Riduwan dan Engkos. (2012). Cara Menggunakan dan Memakai Analisis Jalur. Bandung: ALFABETA.

Rizan, M dan Elestia. (2009). Pengaruh Citra Toko, Private Brand dan Kualitas Pelayanan terhadap Kepuasan Pelanggan dan Loyalitas Pelanggan Supermarket. Jurnal Aktualita Manajemen 5(1). 23 hal.

Sondoh, S. L., Omar, M. W., Wahid, N. A., Ismail, I., \& Haru, A. (2007). The Effect of Brand Image on Overall Satisfaction and Loyalty Intention in the Context of Color Cosmetic. Journal Asian Academy of Management, 12(1): 83-107.

Sugiyono. (2011). Metode Penelitian Kuantitatif, Kualitatif dan .R\& D. Bandung: Alfabeta. Tjiptono, Fandy. (2000). Prinsip \& Dinamika Pemasaran. Edisi Pertama. Yogyakarta: J \& J Learning.

Tjiptono, F. (1996), Strategi Bisnis dan Manajemen, Penerbit Andi, Yogyakarta

Unknown, Hero Supermarket: Retail dari www.oxfordbusinessgroup.com/analysis/herosupermarket-retail

Utami, Cristina W, (2006). Manajemen Ritel (Strategi dan Implementasi Ritel Modern); Jakarta: Salemba Empat.

Utama, Agung, (2003), Analisis Pengaruh Persepsi Kualitas Pelayanan Terhadap Kepuasan Pelanggan Rumah Sakit Umum Cakra Husada Klaten, OPSI, vol 1, no 2, Yogyakarta 
INOBIS: Jurnal Inovasi Bisnis dan Manajemen Indonesia

Volume 02, Nomor 04, September 2019

Nerys Lourensius L.T, Tony Wijaya

Wijaya, Tony, (2008), Pengaruh Kepuasan Pada Penanganan Keluhan Dan Citra Perusahaan Terhadap Loyalitas Konsumen Natasha Skin, STIE IEU, Yogyakarta.

Wilkie, Williem L, (1994), Consumer Behavior, $3^{\text {rd }}$ ed. John Wiley \& Sons, Inc. www.topbrand-award.com 